\title{
Proceeding
}

Supplementary Issue: Rio 2016 Olympic Games Second Anniversary Special Edition. Olympic Studies Forum, 2-3 October 2018.

Federal University of Espirito Santo, (Vitória - Espirito Santo), Brazil

\section{Sport as a medium for the development of virtuous man}

\author{
RICARDO VELA DE BRITTO PEREIRA \\ Nova Acrópole, Madrid, Spain
}

\begin{abstract}
This paper proposes a philosophical reflection based on the purpose of sport and its relationship with victory, so sought in the Olympic Games since antiquity. Philosophy deals with the pursuit of the wisdom that comes from innumerable forms, with sport being one of them. The philosophy of the sport is called Olympism and its promotion is one of the responsibilities of the Brazilian Olympic Academy. Sport is a means to achieve a greater purpose, the development of the virtuous human being. When the purpose is lost, the sport ceases to fulfill its function. This study found a strong association between values that have been discussed in antiquity and which serve as experience for the present moment. Keywords: Philosophy of sport; Symbol; Virtues; Values.
\end{abstract}

\section{Cite this article as:}

Vela de Brito, R. (2019). Sport as a medium for the development of virtuous man (in Portuguese). Journal of Human Sport and Exercise, 14(3proc), S316-S320.

doi:https://doi.org/10.14198/jhse.2019.14.Proc3.04

Corresponding author. Nova Acrópole, Madrid, Spain.

E-mail: snesporte@nova-acropole.org.br

Supplementary Issue: Rio 2016 Olympic Games Second Anniversary Special Edition. Olympic Studies Forum, 2-3 October 2018. Federal University of Espírito Santo, (Vitória - Espírito Santo), Brazil.

JOURNAL OF HUMAN SPORT \& EXERCISE ISSN 1988-5202

(c) Faculty of Education. University of Alicante

doi:10.14198/jhse.2019.14.Proc3.04 


\section{INTRODUÇÃO}

Desde a pré-história até os dias atuais, encontram-se uma variedade de métodos empregados para educação, assim como uma variedade de finalidades. O Barão Pierre de Coubertin, idealizador dos Jogos Olímpicos da Era Moderna, promove o desenvolvimento do ser humano através do esporte e este trabalho apresentará o símbolo e as cerimônias como elementos importantes na obtenção de virtudes.

Diante deste cenário, Coubertin propõe uma educação esportiva baseada na filosofia do olimpismo. Em diversas oportunidades aborda o tema e relata que 0 esporte pode incitar valores nobres ou paixões baixas e, por fim, chega a mencionar a possibilidade de ser usado para solidificar a paz ou preparar para a guerra (Olimpismo..., p.313, 2009).

Este filósofo via no olimpismo uma forma de atingir um objetivo maior do que apenas jogos ou exercícios. Seu estudo em cima do conhecimento das tradições antigas, gregas e romanas, trabalha, por exemplo, a abertura dos jogos olímpicos de maneira cerimonial. Em Todt (2006), observa-se que os Jogos Olímpicos diferem-se das demais competições devido à sua bagagem cultural e, de acordo ao mesmo autor, observase a importância dos símbolos e das cerimônias para compreensão de valores como respeito mútuo, equidade, justiça, igualdade entre outros. Os elementos da cerimônia, segundo explica Todt (2009), não estão dispostos de maneira aleatória e carregam em si tais ensinamentos. Em Durántez (2008), verifica-se que as solenidades festivas dos jogos modernos tiveram um complexo e rico antecedente em Olímpia, aborda seu caráter ritualístico e relaciona este rito a um ato religioso por ter um deus, neste caso Zeus, como patrono dos jogos. 0 presente estudo não enxerga esses ritos de maneira religiosa, mas reconhece o valor do rito para formação do ser humano, ao concordar que o mundo atual e os jogos Olímpicos como uma de suas mais importantes manifestações, necessitam da espiritualidade que os símbolos e as cerimônias proporcionam, como eficaz elemento de luta contra o materialismo e a vulgaridade comum (Durántez, p.16, 2008).

Segundo Todt (2009), fazendo referência ao Comitê Olímpico Internacional (COI,1996): As cerimônias representam um dos principais meios nos quais o COI manifesta seu significado e 0 torna visível para as grandes audiências, ... apresentam uma oportunidade de educação popular e pesquisa profissional dentro de instituições, na dinâmica do Movimento Olímpico e do amplo sistema global. (Todt, p. 115, 2009).

A partir dessa perspectiva, o presente estudo aborda um dos principais símbolos de Olímpia, Zeus de Fídias, patrono do santuário dos jogos e uma das sete maravilhas do mundo antigo. $O$ foco é o contato com a deusa Nike, deusa da vitória, representada junto a Zeus, que estende a mão oferecendo a todos os atletas e espectadores o contato com a deusa e, através dela, entender a essência por trás desse símbolo tido como 0 deus regente das festividades olímpicas e como pode nos inspirar nesse caminho de busca pelo desenvolvimento humano através do esporte.

\section{O ZEUS DE FÍDIAS}

Segundo Platão, em sua obra Fedro (1998), Zeus é o deus da amizade, porém esta amizade não é sustentada em um companheirismo de ócio e uma indiferença cúmplice; Zeus toma suas decisões pensando naquilo que realmente é bom para todos, conquistando a capacidade de governar o Olimpo, a morada dos deuses, segundo a tradição da cultura grega. Zeus sendo a principal divindade do panteão grego, corresponde dizer então que o espírito de amizade governa os Jogos e está sentado sobre um trono ornado com ouro, assim como Nike, o espírito da vitória. 
Platão fala sobre quatro classes de homens: homens de ferro, de bronze, de prata e de ouro. Os homens de ouro, são aqueles que carregam valores dentro de si e por isso não precisam se corromper em busca dos valores externos. Os homens de ferro, não encontram valores claros dentro de si e são facilmente corrompidos.

Segundo a visão platônica, apenas os homens de ouro, que travam a batalha consigo mesmo, conhecem realmente Nike e tem o mérito de receber dela a coroa de louros. O homem de ferro buscará os valores externos e assim também buscará a vitória externa, a vitória sobre o oponente, que não chega a conhecer a face da verdadeira deusa, segundo a tradição. O homem de ouro é o único capaz de não enferrujar por dentro, visto que já reconhece a vitória dentro de si.

O cetro segurado pela mão de Zeus representa a união entre o mundo material e espiritual, tendo no seu topo uma águia, símbolo do poder espiritual. Na mitologia, a espiritualidade vem do contato com os deuses e neste caso é o contato com o espírito da amizade e a vitória. Entrar em contato com esses valores não significa, para os filósofos da época, estar atrelado a uma religião. Para eles, os deuses não são propriedades da religião, mas representam ideias perfeitas das quais as diferentes áreas do conhecimento buscam alcançar.

No quadro abaixo sintetiza os principais símbolos que conformam a imagem de Zeus de Fídias:

Quadro 1. Símbolos que conformam a imagem de Zeus de Fídias

\begin{tabular}{|l|l|}
\hline Símbolo & Significado \\
\hline Zeus & Patrono da amizade e dos Jogos (Platão, Fédro, p.25,1998) \\
\hline Nike & Deusa da Vitória Interior (Schwarz, p.134, 2017) \\
\hline Cetro & Unificação do mundo material e espiritual (Hamilton, tradução nossa, p. 467, 2011) \\
\hline Águia & Símbolo de poder (Hamilton, tradução nossa, p. 467, 2011) \\
\hline Coroa de Louros & Coroação sobre a matéria (Platão, As Leis, p. 184;167, 2012) \\
\hline Ouro & Homem de ouro que descobriu os valores dentro de si. (Platão, A República, p.81, 1997) \\
\hline
\end{tabular}

De acordo com Platão, em sua obra Teeteto (2001), a vitória pressupõe duas ou mais partes, para que uma das partes vença a(s) outra(s). O ser humano que não consegue enxergar as duas partes dentro de si, uma boa e outra ruim, acabará por lutar contra um oponente externo e só valorizará aquele que traz títulos em cima dos demais. Este é um dos problemas principais abordados por este trabalho e que já na época de Sócrates era discutido.

Segundo a tradição clássica, os jogos e campeonatos remontam a própria vida. Ali o atleta passa por pressões, tem que lidar com a ansiedade, com seus medos, vaidades. Também deve aprender a vencer a comodidade, preguiça, fuga do esforço e fraqueza diante dos instintos. É uma oportunidade para começar a enxergar suas fraquezas através do esporte e assim levar esse aprendizado para a vida.

Sendo assim, é importante encontrar um oponente a altura, pois ao encontrar um oponente de menor nível, a dificuldade diminui e não se torna possível o embate interno. Esta era uma busca constante nos mitos de cavalaria do Rei Arthur. Os cavalheiros buscavam outros cavalheiros valorosos, para competirem, mas ao final da luta reconheciam o valor de seu oponente e agradeciam pela oportunidade de permitir que 
enxergassem suas limitações internas (relacionadas com o controle do emocional) e externas (relacionada com as habilidades físicas).

O papel do treinador e do capitão é o de mostrar esta realidade que ocorre no emocional do atleta e ajudálos a chegar a um lugar psicológico seguro. Joseph Campbell, (1991), em sua obra "O poder do mito", relata a passagem de um adolescente para a vida adulta e como um dirigente pode levá-lo a ter uma experiência mística. Caso não consiga fazê-lo, o jovem pode ter um colapso psicológico.

Para uma pessoa que começa a jogar vôlei por exemplo, o colapso psicológico poderia vir quando o jogador se sente um peso no time, errando passes, levantadas, saques, etc... Para isso existe 0 treino. 0 jogador iniciante deve passar por três passos: "Eu quero", "Eu posso" e "Eu faço". Primeiro precisa querer, o professor acompanha no segundo passo mostrando que o aluno é capaz de fazer, construindo dentro de si o sentimento do eu posso e por fim o jogador é capaz de fazer sozinho e está apto a jogar. Aqui se alcança a experiência mística e 0 atleta pode interagir na sociedade, fazer amizades e sair vitorioso ainda que não vença do outro time.

\section{CONSIDERAÇÕES FINAIS}

Este resumo buscou reforçar a importância dos símbolos, reconhecendo a linguagem cerimonial como simbólica, a partir de textos modernos e antigos, junto com a experiência prática esportiva realizada pelos autores, tendo como um dos principais objetivos robustecer que finalidades claras podem levar à construção de um mundo melhor, se alinhados com o pensamento de Pierre de Coubertin, que afirma enxergar no esporte um meio para estabelecer entre os jovens "o equilibrio rompido há muito tempo entre corpo e espírito" (OLIMPISMO, p. 58, 2015).

Embora um resumo estendido não ofereça espaço suficiente para fazer um estudo mais profundo deste assunto, os autores esperam, junto com as referências bibliográficas dos especialistas em olimpismo, mitólogos da atualidade e dos filósofos da antiguidade, terem oferecido um norte sustentado nas virtudes. Este trabalho terá prosseguimento através da Escola do Esporte com coração, desenvolvida pela Organização Internacional Nova-Acrópole, que seguirá desenvolvendo seus estudos voltados para filosofia do olimpismo.

\section{REFERÊNCIAS}

Campbell, Joseph. O poder do mito. São Paulo: Palas Athena, 1990. Org. por Betty Sue Flowers ; tradução de Carlos Felipe Moisés.

Coubertin, Pierre de, Olimpismo: seleção de textos, Comitê Internacional Pierre de Coubertin, Porto Alegre: ediPUCRS, 2015. Editores Norbet Muller e Nelson Schneider Todt; Tradutor: Luiz Carlos Bombassaro. ISBN: 978-85-397-0736-2. https://doi.org/10.15366/citius2017.10.2.004

Durántez, Conrado. El Fuego de Olímpia. Espanha: Comitê Olímpico Espanhol, 2008.

Hamilton, Edith. Mythology: Timeless Tales of Gods and Heroes. New York: Grand Central Publishing; Reprintedition (January 1, 2011). ISBN-10: 0446574759; ISBN-13: 978-0446574754.

Olimpismo e educação Olímpica no Brasil, 1.ed.edição: 2009. Porto Alegre: Ed. UFRGS. ISBN 978-85386-0053-4.

Platão. Teeteto; Crátilo. 3.ed. rev.Belém(PA): Ed. Universitária UFPA., 2001. Tradução direta do grego Carlos Alberto Nunes Coordenação Benedito Nunes.

Platão. Fédro. Lisboa:Guimarães, 1998. 
Platão. As leis. São Paulo: Loyola, 2012. ISBN-13: 9788515038794; ISBN-10: 851503879X.

Platão.A República. São Paulo: Editora Nova Cultural Ltda.; Circulo do LívroLtda, c 1997. Tradução: Enrico Corvisieri Direitos exclusivos sobre a tradução deste volume, Editora Nova Cultural Ltda., ISBN 85-351-1004-6.

Schwarz, Fernando Felix. O Sagrado Camuflado: a crise simbólica do mundo atual, 1a. Ed., Belo Horizonte: Edições Nova Acrópole, 2017.

Todt, N. Educação Olímpica: em direção a uma nova Paidéia. 2006. 182 f. Tese (Doutorado em Educação)-Faculdade de Educação, PUCRS, Porto Alegre, 2006.

Todt, Nelson Scheneider . As cerimônias de abertura dos jogos olímpicos de verão, sob uma perspectiva da Educação Olímpica. In: Olimpismo e educação Olímpica no Brasil, 1.ed.edição: 2009. Porto Alegre: Ed. UFRGS. ISBN 978-85-386-0053-4. https://doi.org/10.5585/podium.v3i1.81

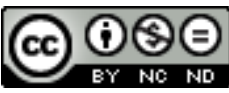

This work is licensed under a Attribution-NonCommercial-NoDerivatives 4.0 International (CC BY-NC-ND 4.0). 